\title{
Determinação de clorofila em mudas de Balfourodendron riedellianum (Engl.) Engl. e Cedrela fissilis Vell. submetidas à desfolha artificial
}

\section{Determination of chlorophila in seedlings of Balfourodendron riedellianum (Engl.) Engl. and Cedrela fissilis Vell. submitted the artificial defoliation}

\author{
Maria Eunice Lima Rocha ${ }^{1(*)}$ \\ Patrícia Gibbert ${ }^{2}$ \\ Tatiane Priscila Chiapetti ${ }^{3}$ \\ Marlene de Matos Malavasi ${ }^{4}$ \\ Ubirajara Contro Malavasi ${ }^{5}$
}

\section{Resumo}

O objetivo do trabalho foi avaliar a variação de clorofila $a, b$ e totais em mudas de Balfourodendron riedellianum (Engl.) Engl. e Cedrela fissilis Vell. sobre desfolha artificial pelo método destrutivo e não destrutivo. O delineamento utilizado foi o inteiramente casualizado, composto de 2 tratamentos (com e sem desfolha artificial) e 20 repetições, totalizando 40 unidades experimentais por espécie. As espécies não foram comparadas estatisticamente, já que apresentam constituição geral totalmente diferente, dessa maneira, são tratadas como experimentos distintos. Ao final do experimento foram determinados os teores de clorofila pelo método bioquímico e analítico, com o uso do clorofilômetro. Em relação ao maior teor de clorofila encontrado em mudas de cedro submetidas a desfolha artificial, isso pode ser explicado pela característica da espécie perder as folhas em determinadas fases de desenvolvimento (caducifólia), ou seja, esta já apresenta estratégias para compensar a fotossíntese mesmo com o número de folhas reduzido. Os teores de clorofila totais determinados pelo método destrutivo foram crescentes nas espécies, enquanto que as médias obtidas em mudas expostas a desfolha artificial foram de 58,12 e 47,62 $\mu \mathrm{mol} \mathrm{m} \mathrm{m}^{2}$, em cedro e pau marfim. Em relação aos métodos de determinação dos pigmentos fotossintéticos, é perceptível que ambos são eficientes na quantificação desse parâmetro, dependendo do objetivo proposto.

Palavras chaves: Clorofilômetro; Lenhosas; Quantificação.

I Msc.; Agronoma; Universidade Estadual do Oeste do Paraná, Unioeste; Endereço:Tv. Pau Amarelo, s/n, Vila Nova, CEP: 68650-000, Capitão Poço-PA, Brasil. E-mail: eunice_agronomia@yahoo.com.br (*) Autor para correspondência

2 Msc.;Agronoma; Universidade Estadual do Oeste do Paraná, Unioeste; Endereço: Rua Pernambuco, I777, Centro, CEP: 8560-000, Marechal Candido Rondon-PR, Brasil. E-mail: patriciagibbert@gmail.com

3 Msc.; Agronoma; Universidade Estadual do Oeste do Paraná, Unioeste; Endereço: Rua Pernambuco, 1777, Centro, CEP: 8560-000, Marechal Candido Rondon-PR, Brasil.E-mail: tatianechiapetti@gmail.com

4 Dra.; Engenheira Agrônoma; Professora na Universidade Estadual do Oeste do Paraná, Unioeste, Centro de Ciências Agrárias; Endereço: Rua Pernambuco, 1777, Centro, CEP: 8560-000, Marechal Candido Rondon-PR, Brasil. E-mail: marlenemalavasi@yahoo.com.br

5 Dr.; Engenheiro Florestal; Professora na Universidade Estadual do Oeste do Paraná, Unioeste, Centro de Ciências Agrárias; Endereço: Rua Pernambuco, 1777, Centro, CEP: 8560-000, Marechal Candido Rondon-PR, Brasil. E-mail: biramalavasi@yahoo.com.br

Recebido para publicação em 08/10/2016 e aceito em 18/11/2019

\begin{tabular}{llllll}
\hline Ambiência & Guarapuava (PR) & v.l5 n.2 & p. $435-443$ & Maio/Ago 2019 & ISSN 1808 - 025I
\end{tabular}




\section{Abstract}

The objective of this work was to evaluate the variation of chlorophyll a, b and total in Balfourodendron riedellianum (Engl.) Engl. and Cedrela fissilis Vell. about artificial defoliation by the destructive and non destructive method. A completely randomized design was used, consisting of 2 treatments (with and without artificial defoliation) and 20 replications, totaling 40 experimental units per species. The species were not statistically compared, since they have a totally different general constitution, thus, they are treated as distinct experiments. At the end of the experiment, chlorophyll levels were determined by the biochemical and analytical method, using the chlorophyll meter. Regarding the higher chlorophyll content found in cedar seedlings submitted to artificial defoliation, this can be explained by the characteristic of the species losing leaves at certain stages of development (deciduous), that is, it already has strategies to compensate for photosynthesis even with the number of sheets reduced. The total chlorophyll content determined by the destructive method were increasing in the species, while the averages obtained in seedlings exposed to artificial defoliation were 58.12 and $47.62 \mu \mathrm{mol} \mathrm{m} 2$ in cedar and ivory wood. Regarding the photosynthetic pigment determination methods, it is noticeable that both are efficient in quantifying this parameter, depending on the proposed objective.

Keywords: Chlorophyll meter; Woody; Quantification.

\section{Introdução}

Muitos estudos têm enfatizado o aumento da degradação de matas nativas, assim, estratégias devem ser desenvolvidas acerca do meio ambiente, com o objetivo de manejar a floresta de forma mais sustentável, equilibrando o ecossistema e levando em consideração os aspectos econômicos e sociais (DEGEN et al., 2013). Assim, desenvolver pesquisas com espécies nativas é de extrema importância, pois respalda o uso das mesmas, nas mais diversas condições e alterações que podem ser submetidas, desde a produção de mudas até o estabelecimento em campo.

Balfourodendron riedelianum (Engl.) Engl. ou pau-marfim da família Rutaceae é considerada uma espécie caducifólia, longeva pertencente ao grupo Sucessional das secundárias tardias. A madeira do pau marfim pode ser usada para fabricação de móveis de luxo, molduras, guarnições internas, portas, artefatos domésticos, peças torneadas, laminados decorativos, tacos para assoalhos, carpintaria e marcenaria em geral. A espécie pode atingir uma altura aproximada de $35 \mathrm{~m}$ e diâmetro de $100 \mathrm{~cm}$ quando adultas, além de serem variável em função da conformidade, podendo apresentar tronco cilíndrico ou retilíneo (PAULA; ALVEZ, 2017).

Cedrela fissilis Vell. ou cedro da família Meliaceae é uma planta de grande porte e comportase como secundária inicial. A madeira dessa espécie apresenta grande valor econômico com uso potencial para arborização, paisagismo, perfumaria e medicinal, além de ser indicada para recomposição de mata ciliar (SAKURAGUI et al., 2013).

A exploração da espécie muitas vezes desordenada no passado, fez com que as reservas naturais de cedro diminuíssem progressivamente durante os anos, gerando, assim, grandes dificuldades na aquisição de sementes e materiais genéticos para estudos (CAIRES et al., 2011). 
Injúrias ou perdas foliares sejam naturais ou artificiais podem induzir alterações fisiológicas, bioquímicas e estruturais nas plantas. A quantificação das perdas e do prejuízo econômico pode incentivar o silvicultor a melhorar as práticas de manejo e reduzir os danos causados pelos insetos. Contudo, a simulação exata do consumo de folhas provocado por insetos é extremamente difícil na prática. Portanto, é mais frequente que sejam encontradas na literatura pesquisas realizadas com injúrias artificiais (COSTA et al., 2003; DRANSKI et al., 2016).

Tradicionalmente, os métodos utilizados para determinação do teor de clorofila requerem destruição das folhas, o que é uma desvantagem em estudos que visam analisar o efeito dos tratamentos no grau de esverdeamento. Além disso, esses métodos são muito demorados e onerosos. A partir da década de 90, foi disponibilizado equipamento capaz de gerar grandezas relacionadas com os teores de clorofila, o clorofilômetro Soil Plant Analysis Development (SPAD-502). Esse instrumento portátil fornece leituras que se relacionam com o teor de clorofila das folhas permitindo medições de forma rápida e prática a um custo baixo (RICHARDSON et al., 2002; JESUS; MARENCO, 2008).

Realizar a quantificação dos teores de clorofilas em mudas submetidas à desfolha é de primordial importância, principalmente, por estes pigmentos estarem envolvidos na produção de fotossintatos. Logo, a perda de folhas ou de parte dela, irá refletir no crescimento e desenvolvimento das mudas e, neste sentido, esse parâmetro se torna um importante sinalizador bioquímico da desfolha.

Diante do exposto, o objetivo da pesquisa foi avaliar a variação nos teores de clorofila pelo método destrutivo e não destrutivo em mudas de Balfourodendron riedellianum E. e Cedrela fissilis V. submetidas à desfolha artificial.

\section{Material e métodos}

O ensaio foi realizado em casa de sombra localizado sob as coordenadas de $24^{\circ} 33^{\prime} \mathrm{S}$ e $54^{\circ} 04^{\prime}$ W e altitude de $420 \mathrm{~m}$. De acordo com o IAPAR e, segundo a classificação de Koppen, o clima da região é do tipo Cfa subtropical, mantendo a média anual de temperatura entre 22 e $23^{\circ} \mathrm{C}$, com chuvas bem distribuídas durante o ano e verões quentes (ALVARES et al., 2013; NITSCHE et al., 2019).

O ensaio utilizou mudas de pau marfim e de cedro com aproximadamente oito meses, transplantadas para vasos de 2 litros preenchidos com substrato Plantmax ${ }^{\circledR}$ e aclimatadas por 15 dias antes da imposição dos tratamentos. As plantas receberam adubações semanais com $3 \mathrm{~mL}$ por muda de solução nutritiva (Tabela 1) antes da imposição do tratamento.

\section{Tabela 1- Composição da solução nutritiva para adubação de mudas}

\begin{tabular}{cccccc}
\hline \multicolumn{5}{c}{ Solução nutritiva } \\
\hline KH2PO4 & MgSO4 & KNO3 & Ca(NO3)2 4H2O & Micro Completa & Fe-EDTA \\
& & \multicolumn{5}{c}{ mL L-1 } & 1,0 & 1,0 \\
\hline
\end{tabular}

Após 15 dias da imposição dos tratamentos, foram determinados os teores de clorofila pelos métodos destrutivos (ou bioquímico) e não destrutivo (clorofilômetro Minolta ${ }^{\circledR}$ SPAD-502). Em ambos, coletaram-se as informações de clorofila em folhas do terço médio da folhagem localizadas nos pontos cardinais da muda. Com as quatro leituras, calculou-se a média utilizando-se o SPAD. 
Imediatamente após o término das leituras, as folhas foram destacadas, acondicionadas em sacos e submetidas à metodologia proposta por Arnon (1949) com supressão das fases de trituração e centrifugação.

Amostras foliares de 14,0 $\mathrm{cm}^{2}$ foram acondicionadas em tubos Falcon de 15,0 $\mathrm{cm}^{3}$, previamente revestidos com papel alumínio e preenchidos com $10 \mathrm{~mL}$ de acetona a $80 \%$. As amostras permaneceram incubadas a $25^{\circ} \mathrm{C}$ por $48 \mathrm{~h}$. Ao término do período de extração, alíquotas de $3 \mathrm{~mL}$ foram transferidas para cubetas de quartzo de $3,0 \mathrm{~cm}^{3}$ e tomados os valores de absorbância nos comprimentos de 645 e $663 \mathrm{~nm}$. Os resultados para a concentração de clorofila a, clorofila b, e clorofila $\mathrm{a}+\mathrm{b}$ foram obtidos conforme as Equações 2, 3 e 4 propostas por Arnon (1949) e

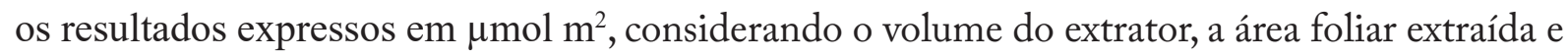
a massa molar das clorofilas a e b.

$$
\begin{aligned}
& \text { Clorofila } \mathrm{a}=12,7 \mathrm{~A}_{663}-2,69 \mathrm{~A}_{645} \\
& \text { Clorofila } \mathrm{b}=22,9 \mathrm{~A}_{645}-4,68 \mathrm{~A}_{663}
\end{aligned}
$$

Clorofila $\mathrm{a}+\mathrm{b}=$ Clorofila $\mathrm{a}+$ Clorofila $\mathrm{b}$

O delineamento experimental utilizado foi o inteiramente casualizado composto por dois tratamentos (com e sem desfolha artificial) e 20 repetições por espécie, totalizando 40 unidades experimentais. Para a imposição dos tratamentos, realizou-se a contagem das folhas e a partir disso, $40 \%$ delas foram retiradas de cada muda, com exceção das plantas controle, ou seja, nas quais não foram realizadas a desfolha artificial.

Os dados obtidos foram submetidos aos testes de normalidade e homogeneidade seguido da análise de variância. Quando da existência de significância, as médias foram comparadas pelo teste de Tukey a 5 \%, com auxílio do software SISVAR 5.6.

\section{Resultados e discussão}

Ao se avaliarem os tratamentos com e sem desfolha, observa-se que houve diferença estatística para as duas espécies e para todas as variáveis analisadas, entre elas, clorofila a, b, totais e o método de determinação não destrutivo.

O método de determinação bioquímico de clorofila a resultou nos menores teores em folhas com injurias, com média de 34,15 $\mu \mathrm{mol} \mathrm{m} \mathrm{m}^{2}$ e $24,88 \mu \mathrm{mol} \mathrm{m} \mathrm{m}^{2}$ em mudas de cedro e de pau marfim, respectivamente (Figura 1). Em mudas sem desfolha, as médias foram de 62,39 $\mu \mathrm{mol}$ $\mathrm{m}^{2}$ em cedro e $66,39 \mu \mathrm{mol} \mathrm{m} \mathrm{m}^{2} \mathrm{em}$ pau marfim. Esses resultados eram esperados, pois uma menor área foliar resulta em menor quantidade dos pigmentos clorofilianos.

Outro resultado interessante é sobre as plantas submetidas a desfolha, onde o cedro apresentou maiores teores nessa condição adversa quando se compara às médias com o pau marfim. Isso é consequência de a espécie perder as folhas em determinadas fases de desenvolvimento (caducifólia), principalmente pelas condições climáticas desfavoráveis, ou seja, esta já apresenta estratégias para compensar a fotossíntese mesmo com o número de folhas reduzido e, consequentemente, manter em funcionamento algumas atividades fisiológicas e bioquímicas.

Em condições normais, as concentrações de clorofila pelo método destrutivo em pau marfim foram maiores, demonstrando que, sob condições ideais, avaliando tanto os fatores intrínsecos dessas plantas quanto os extrínsecos, essa espécie tende a se desenvolver melhor, entretanto, quando exposta a condições estressantes, neste caso a desfolha, as mudas de cedro conseguiram manter as concentrações maiores e mais equilibradas. 
Taiz e Zeiger (2013) relataram que a quantidade de clorofila nas folhas é influenciada por diversos fatores bióticos e abióticos, estando diretamente relacionado com o potencial de atividade fotossintética das plantas. Neste caso, como houve perda de folhas e, consequentemente, perda de área fotossinteticamente ativa, a diminuição nos teores desses pigmentos é justificável.

Cabe ressaltar ainda que as clorofilas são os principais pigmentos cloroplastídicos responsáveis pela captação de radiação solar que, durante o processo de fotossíntese, é convertida em energia química na forma de ATP e NADPH. A determinação dos teores de clorofila na folha é importante porque a atividade fotossintética da planta depende em parte da capacidade da folha para absorver luz (SALLA et al., 2007).

Importante destacar que a desfolha é um aspecto importante na vida da planta, pois pode reduzir a sua taxa de crescimento e alterar seus padrões fenológicos e fisiológicos (FORNARA; DU TOIT, 2007).

Os valores médios de clorofila $\mathrm{b}$ em mudas de pau marfim e cedro sem desfolha foram de 74,51 e 69,97 $\mu \mathrm{mol} \mathrm{m} \mathrm{m}^{2}$, respectivamente (Figura 2). Os teores de clorofila b foram menores quando comparados aos teores de clorofila a, provavelmente porque a clorofila a está presente nos dois tipos de complexo clorofila-proteína, que variam diferentemente sob ação da luz de acordo com Taiz e Zeiger (2013).

Os teores de clorofila totais determinado pelo método destrutivo (Figura 3) foram de 132,35

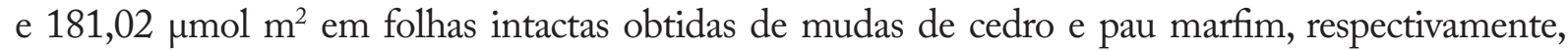
enquanto as médias obtidas de mudas expostas a desfolha artificial foram de 58,12 e 47,62 $\mu \mathrm{mol} \mathrm{m} \mathrm{m}^{2}$, respectivamente. $\mathrm{O}$ estresse imposto pela desfolha resulta em menor área foliar comprometendo a fotossíntese e a produção de energia para o crescimento e desenvolvimento.

Os teores de clorofila determinados com o SPAD foram próximos aos acima reportados. Mudas submetidas à desfolha apresentaram menores teores de clorofilas totais, com média de $40,56 \mu \mathrm{g} \mathrm{cm}^{-2} \mathrm{em}$ mudas de cedro e $34,28 \mu \mathrm{g} \mathrm{cm}^{-2} \mathrm{em}$ mudas de pau marfim (Figura 4). Lôbo et al. (2016) reportaram que concentração máxima de clorofila a com 24 horas de extração foi de $36,36 \pm 0,63 \mu \mathrm{g} \mathrm{cm}{ }^{-2}$ com o mesmo método de determinação de pigmentos.

Interessante destacar que, em condições de estresse, as mudas de Cedrela fissilis apresentaram maiores médias de clorofilas, o que pode refletir em maior resistência ou tolerância da espécie a estresses bióticos e abióticos.

A leitura realizada pelo SPAD é precisa e rápida, entretanto apresenta leitura em unidades arbitrárias (leitura SPAD de conteúdo de clorofila, na faixa de 0 a 99,9). Portanto recomendase que o mesmo seja calibrado com as extrações de clorofilas da cultura de interesse, realizando assim também o método destrutivo (UDDLING et al., 2007). Por esse motivo, há discrepância entre as análises destrutivas e não destrutivas. Além disso, os comprimentos de onda usados para a leitura em SPAD são diferentes da metodologia adotada por Arnon.

A adaptação das plantas às variações na disponibilidade de radiação luminosa, durante a fase inicial do seu desenvolvimento, condiciona mudanças em sua estrutura e metabolismo (FREIBERGER et al., 2010).

A pigmentação foliar pode ser diretamente relacionada com o estresse fisiológico, havendo aumento na concentração de carotenoides e diminuição na concentração de clorofilas em situações de estresse e durante a senescência foliar, limitando o potencial fotossintético e a produção 
Figura 1. Determinação dos teores de clorofila a pelo método bioquímico em mudas de cedro e pau marfim submetidas à desfolha artificial

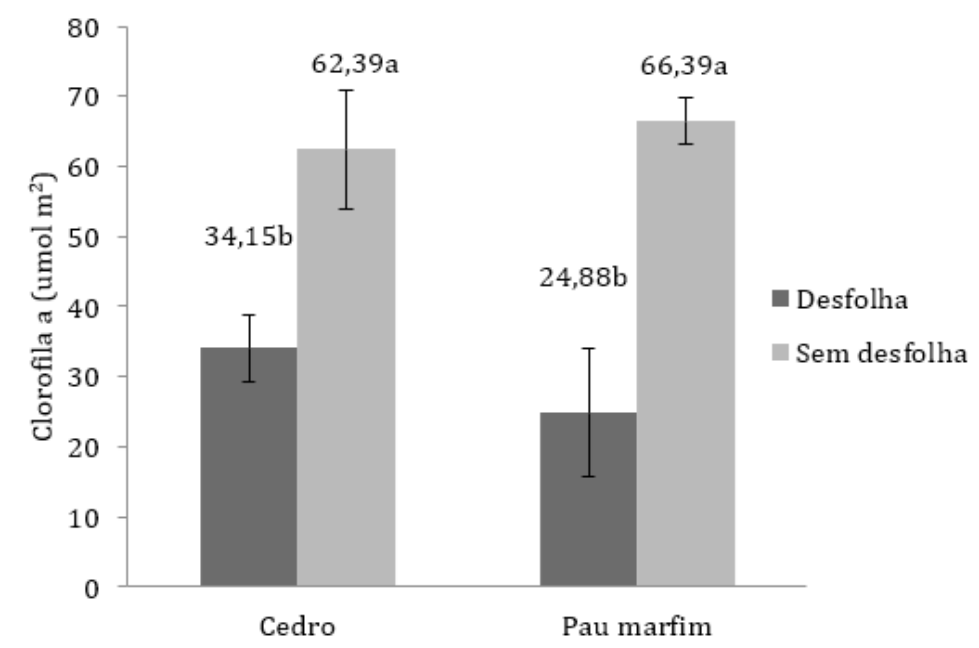

As médias seguidas pela mesma letra não diferem estatisticamente entre si pelo teste de Tukey. As espécies não foram comparadas estatisticamente

\section{Figura 2. Determinação dos teores de clorofila b pelo método bioquímico em mudas de cedro e pau marfim submetidas à desfolha artificial}

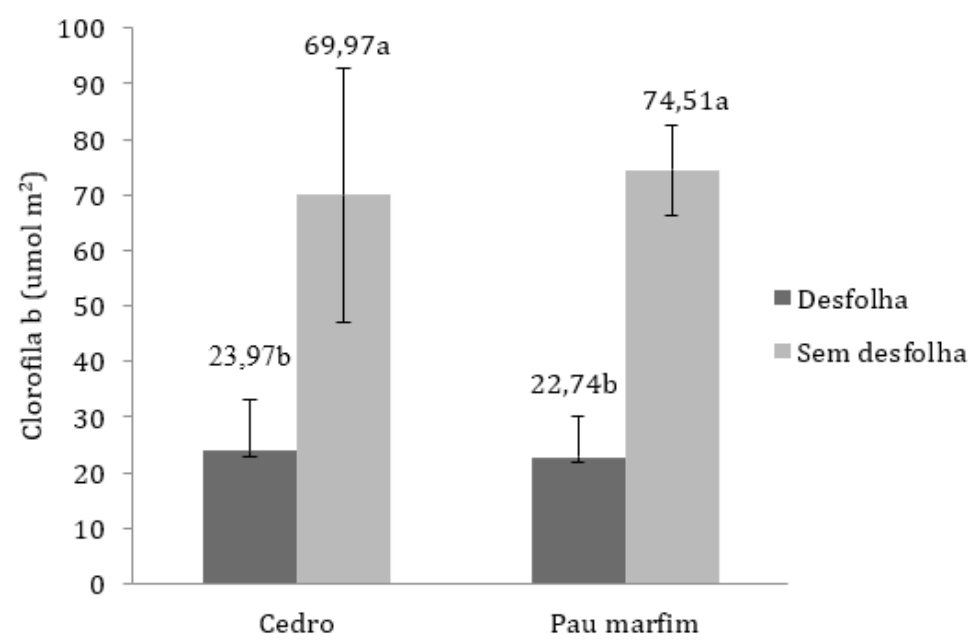

As médias seguidas pela mesma letra não diferem estatisticamente entre si pelo teste de Tukey. As espécies não foram comparadas estatisticamente

primária. Por outro lado, o índice de clorofila em plantas de soja não foi afetado pela desfolha na fase vegetativa (SOUZA et al., 2014).

Estudos com pupunheira mostraram correlação linear da assimilação de $\mathrm{CO}_{2} \mathrm{em}$ função das leituras com clorofilômetro, indicando que esse monitoramento pode ser um meio complementar, rápido e de baixo custo para se estimar importantes eventos fisiológicos naquela espécie (TUCCI et al., 2011).

Quanto ao método de determinação de clorofila, ambos demonstram resultados satisfatórios. A escolha do método é relativa e depende do objetivo; em alguns casos, 
Figura 3. Determinação dos teores de clorofilas totais pelo método bioquímico em mudas de cedro e pau marfim submetidas à desfolha artificial.

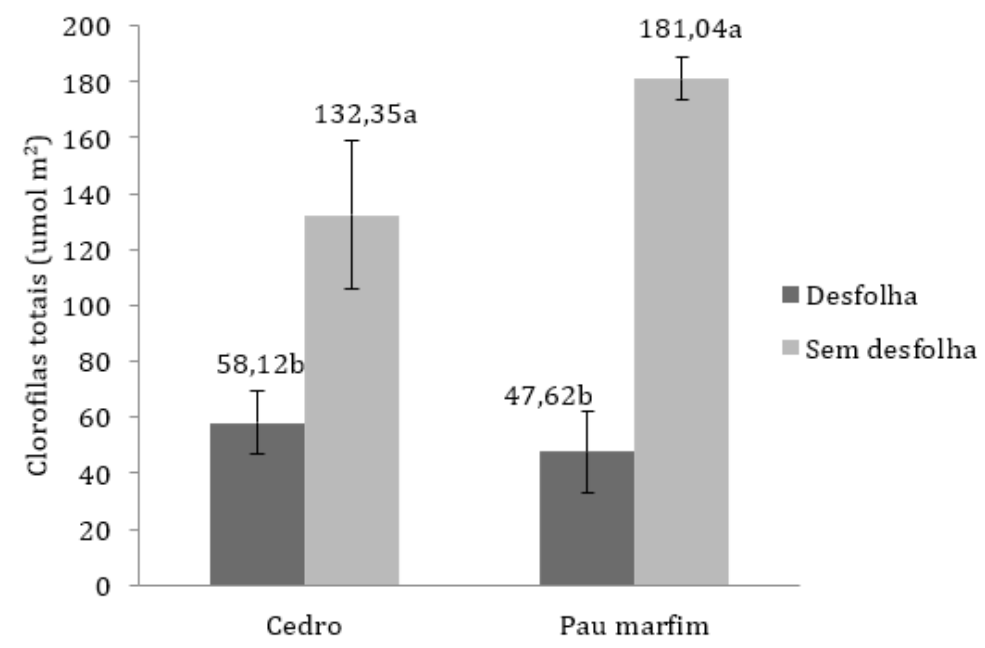

As médias seguidas pela mesma letra não diferem estatisticamente entre si pelo teste de Tukey. As espécies não foram comparadas estatisticamente

Figura 4. Determinação dos teores de clorofilas totais pelo método não destrutivo em mudas de cedro e pau marfim submetidas à desfolha artificial.

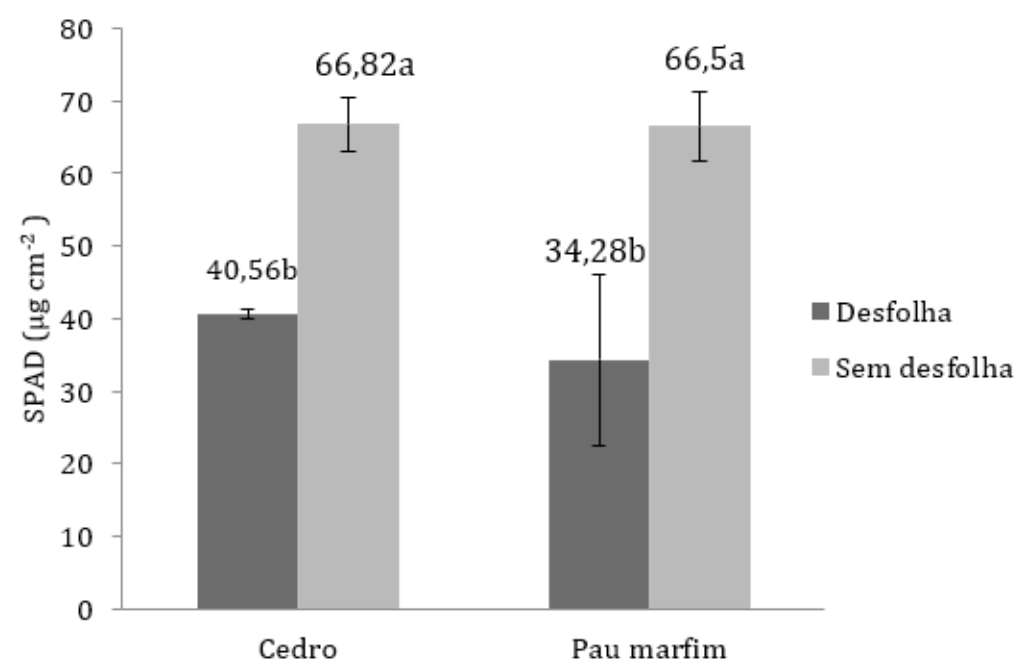

As médias seguidas pela mesma letra não diferem estatisticamente entre si pelo teste de Tukey. As espécies não foram comparadas estatisticamente

recomenda-se que sejam usados os dois, pois um método não anula o outro e pode reforçar os resultados obtidos.

\section{Conclusão}

Os maiores teores de clorofila pelo método destrutivo e não destrutivo foram obtidos em mudas sem desfolha. Isso ocorreu naturalmente porque as folhas submetidas à desfolha reduziram sua área fotossinteticamente ativa e, com isso, houve redução nos pigmentos fotossintéticos, resultando em folhas cloróticas e consequentemente reduzindo a síntese de fotossintatos e metabolismo normal dos vegetais. 
Em relação aos métodos de determinação dos pigmentos fotossintéticos é perceptível que ambos são eficientes na quantificação desse parâmetro. Dependendo do objetivo proposto, é interessante utilizar os dois, já que, o método bioquímico é mais específico. Entretanto, muitas vezes, a análise destrutiva não é vantajosa, pois culmina em perdas nas quantidades das plantas. Dessa maneira, o uso do clorofilômetro se torna muito mais interessante, quando é necessário manter as plantas.

\section{Agradecimento}

À Coordenação de Aperfeiçoamento de Pessoal de Nível Superior - Capes.

\section{Referências Bibliográficas}

ALVARES, C. A.; STAPE, J. L.; SENTELHAS, P. C.; GONÇALVES, J. L. de. M.; SPAROVEK, G. K Köppen's climate classification map for Brazil. Meteorologische Zeitschrift, v. 22, n. 6, p. 711-728, jan. 2013.

ARNON, D.I. Copper enzimas in isolated cloroplasts Polyphenoloxidase in Beta vulgaris. Plant Physiology, Maryland, v.24, n.1, p. 1-15, Jan. 1949.

CAIRES, S. M.; FONTES, M. P. F.; FERNANDES, R. B. A.; NEVES, C. L.; FONTES, R. L. F. Desenvolvimento de mudas de cedro-rosa em solo contaminado com cobre: tolerância e potencial para fins de fitoestabilização do solo. Revista Árvore, Viçosa, MG, v. 35, n. 6, p. 1181-1188, nov./dez. 2011.

COSTA, M.A.G.; BALARDIN, R. S.; ERVANDIL, C. C.; GRÜTZMACHER,A.D.; SILVA, M. T. B. Níveis de desfolha na fase reprodutiva da soja, cv. Ocepar 14, sobre dois sistemas de cultivo. Ciência Rural, v.33, p.813-819, 2003.

DRANSKI, J.; PINTO JUNIOR, A. S.; CAMPGNOLO, M. A.; MALAVASI, U. C.; MALAVASI, M. M. Desenvolvimento inicial de mudas de pinhão manso depende da intensidade de desfolha. MAGISTRA, v. 28, p. 700-709, 2016.

FORNARA, D. A.; DU TOIT, J. T. Browsing lawns? Responses of acacia nigrescens to ungulate browsing in an african savanna. Ecology, v. 88, p. 200-209. 2007.

FREIBERGE, M.B.; CASTOLDI, G.; MARINI, D.; LANG, A.; HERZOG, N.F.; MALAVASI, U.C. Variação sazonal de clorofilas em folhas de Tabebuia avellanedae e Anadenanthera colubrina. Semina, v. 31, p. 1343-1348, 2010.

JESUS, S. V de.; MARENCO, R. A. O SPAD-502 como alternativa para a determinação dos teores de clorofila em espécies frutíferas. Acta Amazônica. Manaus, v. 38, n. 4, p. 815-818. 2008.

LÔBO, L. S.; DALMOLIN, A. C.; MIELKE, M. S. Método não destrutivo para determinação de pigmentos em folhas de Carpotroche brasiliensis. In: IV SEMANA DE ENGENHARIA FLORESTAL DA BAHIA E I MOSTRA DA PÓS-GRADUAÇÃO 
EM CIÊNCIAS FLORESTAIS DA UESB, 2016, Vitória da Conquista. Anais: Perspectiva das florestas plantas brasileiras. 6p.

LOPES, J. L.W. GUERRENI, I. A. SAAD, J. C. C.; SILVA, M. R. da. Nutrição mineral de mudas de eucalipto produzidas sob diferentes lâminas de irrigação e substratos. Revista Brasileira Ciência Solo, Viçosa, MG, v. 31, n. 4, ago. 2007.

MELOTTO, A. NICODEMO, M. L. BOCCHESE, R. A. LAURA, V. A. GONTIJO NETO, M. M.; SCHLEDER, D. D.; POTT, A.; PORFIRIO-DA-SILVA, V. Sobrevivência e crescimento inicial em campo de espécies florestais nativas do Brasil central indicadas para sistemas silvipastoris. Revista Árvore. Viçosa-MG, v.33, n.3, p.425432, 2009.

NITSCHE, P. R.; CARAMORI, P. H.; RICCE, W. da. S.; PINTO, L. F. D. Atlas Climático do Estado do Paraná. Londrina, PR: IAPAR, 2019.

RICHARDSON, A.D.; DUIGAN, S.P.; BERLYN, G.P. An evaluation of noninvasive methods to estimate foliar chlorophyll content. New Phytologist, Lancaster, v.153, n.1, p.185-194, 2002.

SAKURAGUI, C. M.; STEFANO, M. V.; CALAZANS, L. S. B. Meliaceae. Lista de Espécies da Flora do Brasil. Rio de Janeiro: Jardim Botânico do Rio de Janeiro, 2013. 180p.

SALLA, L.; RODRIGUES, J. C.; MARENCO, R. A. Teores de clorofila em árvores tropicais determinados com o SPAD-502. Revista Brasileira de Biociências, Porto Alegre, v. 5, n. 2, p. 159-161, 2007.

SOUZA, V.Q.; NARDINO, M.; FOLLMANN, D.N.; BAHRY, C.A.; CARON, B.O.; ZIMMER, P.D. Caracteres morfofisiológicos e produtividade da soja em razão da desfolha no estádio vegetativo. Científica, Jaboticabal, v.42, n.3, p.216-223, 2014.

TAIZ, L.; ZEIGER, E. Metabolitos secundários e defesa vegetal. In: 13, p. 369-396. . Fisiologia Vegetal. Porto Alegre: Artmed. 2013, cap.

TUCCI, M. L. S.; MODOLO, N. M. E.; MACHADO, E. C. Gas exchanges in peach palms as a function of the spad chlorophyll meter readings. Revista Brasileira de Fruticultura, v. 33, n. 1, p. 267-274, 2011.

UDDLING, J.; GELANG-ALFREDSSON, J.; PIIKKI, K.; PLEIJEL, H. Evaluating the relationship between leaf chlorophyll concentration and SPAD-502 chlorophyll meter readings. Journal Photosynthesis Research, Dordrecht, v.91, n.1, p.37-46, 2007. 